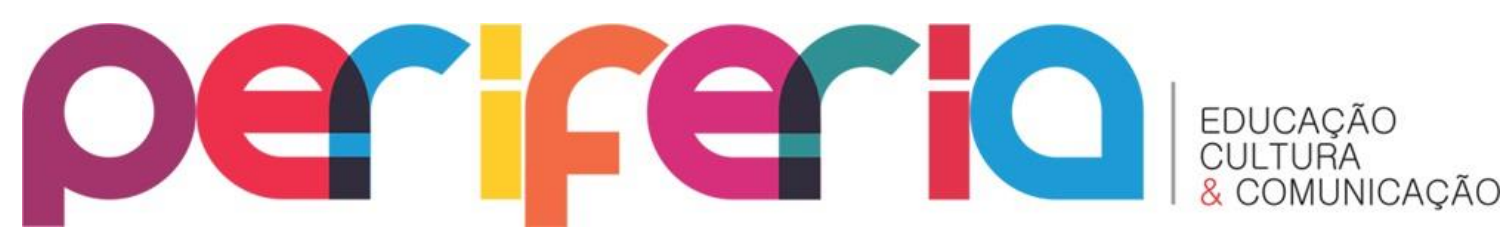

\title{
CENTRO EDUCACIONAL DE NITERÓI: TRAJETÓRIAS E HISTÓRIAS
}

\author{
Ana Cristina Menegaz dos Santos Carpi ${ }^{1}$ \\ Colégio Pedro II \\ Jacqueline de Fatima dos Santos Morais ${ }^{2}$ \\ Universidade do Estado do Rio de Janeiro
}

\section{RESUMO}

Este trabalho é um recorte de dissertação de mestrado, defendida no Programa de Pós-Graduação em Educação da Universidade do Estado do Rio de Janeiro (UERJ), que se refere ao percurso histórico do Centro Educacional de Niterói (CEN). Privilegiamos aqui o "Projeto Político Pedagógico" como fonte documental primária a fim de compreendermos a história desta instituição de ensino. A trajetória singular e imbricada por acontecimentos no campo educativo de caráter nacional permitem afirmar que a criação desta escola está relacionada à luta maior pela hegemonia no campo educacional de modelos pedagógicos e administrativos ligados à Escola Nova.

Palavras-chave: História da educação; memória institucional; história escolar.

\section{EDUCATIONAL CENTER OF NITERÓI: TRAJECTORIES AND STORIES ABSTRACT}

This work is part of a dissertation, advocated in the Programme of Graduate Studies in Education of the University of the State of Rio de Janeiro (UERJ), which refers to the historical route of the Educational Center of Niterói (CEN). We favor here the "Pedagogical Political Project" as a primary source document in order to understand the history of this educational institution. The unique trajectory, imbricated by national events on educational field, suggest that the creation of this institution is related to the larger struggle in the educational field for hegemony of pedagogical and administrative models linked to ideas of the New School.

Keywords: History of education; institutional memory; school history.

\footnotetext{
${ }^{1}$ Mestre em Educação pela Faculdade de Formação de Professores da UERJ. É professora do Ensino Fundamental do Colégio Pedro II. E-mail: anacarpi@oi.com.br

2 Doutora em Educação. Professora adjunta da Faculdade de Formação de Professores da UERJ. É pesquisadora do "Núcleo de Pesquisa e Extensão Vozes da Educação História e Memória das Escolas de São Gonçalo". É Procientista da UERJ e Jovem Cientista do Nosso Estado. E-mail: jacquelinemorais@hotmail.com
} 


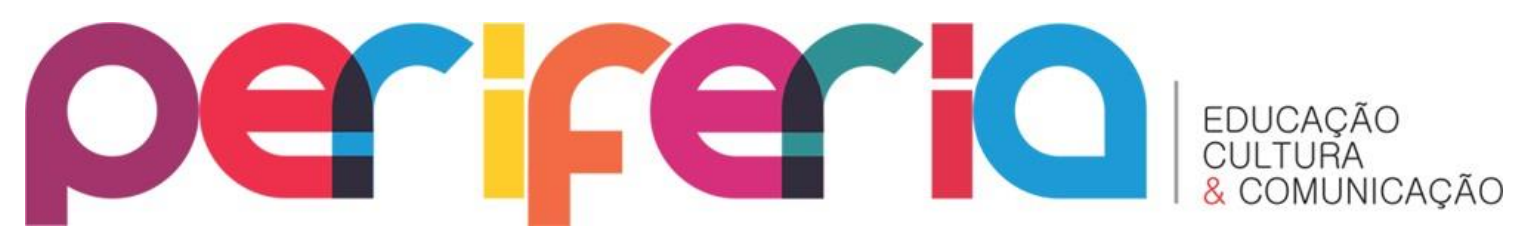

\section{INTRODUÇÃO}

Este trabalho resulta de uma pesquisa desenvolvida entre os anos 2012 e 2013, no âmbito do Programa de Pós-Graduação em Educação, na linha de pesquisa "Formação de Professores, História e Memória", da Faculdade de Formação de Professores da Universidade do Estado do Rio de Janeiro.

Na dissertação de mestrado a que nos referimos acima, texto que originou este artigo, investigamos "o que narram professores da Educação Infantil do Centro Educacional de Niterói (CEN) que atuaram entre 1980-2006, sobre as ações de formação, ou de (trans)formação, vivenciadas no espaçotempo desta escola" (CARPI, 2014, p. 18). Procuramos também compreender os impactos da experiência de ser docente no CEN para a construção da identidade destes professores e para seus fazeres pedagógicos. Para isso, optamos por uma abordagem metodológica de cunho qualitativo. Definimos como sujeitos da pesquisa, a partir do entrelaçamento de critérios diversos, cinco docentes, procedendo a escuta de suas histórias e experiências pessoais, resultando um conjunto de narrativas de enfoque autobiográfico. Recorremos à análise de conteúdo (BARDIN, 2009), mais precisamente à análise categorial temática, já que esta nos permitia maior compreensão das experiências narradas durante a pesquisa.

Bardin (2009) define análise de conteúdo como uma abordagem que consiste em um...

[...] conjunto de técnicas de análise das comunicações visando obter, por procedimentos, sistemáticos e objetivos de descrição do conteúdo das mensagens, indicadores (quantitativos ou não) que permitam a inferência de conhecimentos relativos às condições de produção/recepção [...] destas mensagens. (BARDIN, 2009, p. 42).

O tratamento dado às narrativas não foi o quantitativo; não houve preocupação com dedução frequencial, em enumerar a ocorrência de uma mesma palavra frequentemente repetida, para futuras elaborações de gráficos ou estatísticas. Optamos pela análise categorial - que, segundo Bardin, "funciona por operações de desmembramento do texto em unidades, em categorias segundo reagrupamento 


\section{periferio}

analógicos" (BARDIN, 2009, p. 153) -, privilegiando a análise categorial temática.

Com relação à história do Centro Educacional de Niterói, aspecto tratado na dissertação, privilegiamos como fontes primárias, documentos oficiais elaborados pela própria instituição: o "Estatuto da Fundação Brasileira de Educação - 1992" (FUNDAÇÃO BRASILEIRA DE EDUCAÇÃO, 1994), o "Regimento Interno do Centro Educacional de Niterói" (FUNDAÇÃO BRASILEIRA DE EDUCAÇÃO, 2004); e, principalmente, o "Projeto Político Pedagógico do Centro Educacional de Niterói" (CENTRO EDUCACIONAL DE NITERÓI, 2003). A partir dos dados encontrados nestas fontes, cotejamos com fontes de naturezas diversas: fotos, notícias de jornal, impressos e depoimentos, procedimento fundamental para compreendermos representações e versões acerca da história da instituição.

Os limites impostos pela natureza deste artigo nos obrigam a fazer um recorte da pesquisa acima apresentada, trazendo para este texto o que consideramos mais significativo e original sobre a história do CEN. Esta decisão se deveu ao fato de termos encontrado pouca produção a respeito de uma instituição que foi um marco no que se refere a formação docente e a inovação pedagógica. Assim, optamos por privilegiar neste artigo o "Projeto Político Pedagógico do Centro Educacional de Niterói" (CENTRO EDUCACIONAL DE NITERÓI, 2003)³, e as entrevistas que fizemos com os professores.

A relevância deste trabalho está na possibilidade de contribuir para a história da educação, a partir de uma pesquisa que, buscando aspectos de uma trajetória local, permite diálogos com histórias educacionais mais amplas. Este texto representa nosso esforço por tecer uma síntese, mesmo que limitada e provisória, dessas relações dialógicas entre micro e macro história.

\section{CENTRO EDUCACIONAL DE NITERÓI}

O Centro Educacional de Niterói (CEN) é uma instituição privada de ensino,

\footnotetext{
${ }^{3}$ Este documento foi produzido em setembro de 2001, sofrendo revisões em 2002 e 2003. Esta última versão está servindo de referência a esse texto.
} 


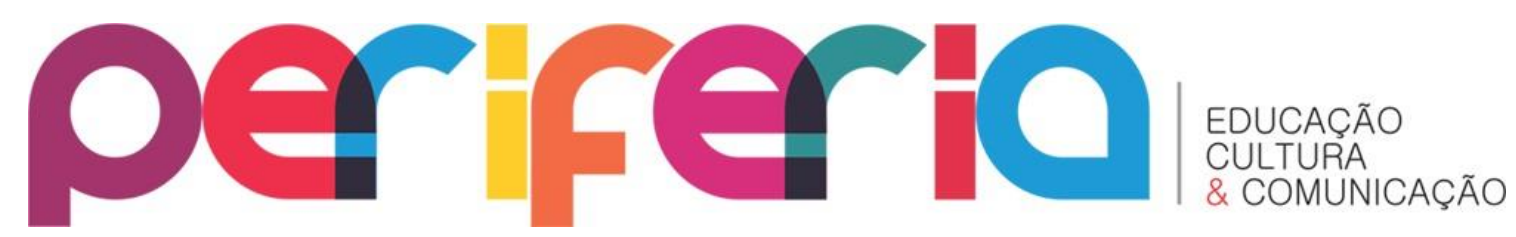

fundada em 1960 e pertencente à Fundação Brasileira de Educação (FUBRAE). A estrutura do CEN divide-se em Escola Básica e Educação de Jovens e Adultos e Capacitação Profissional (DEJAP). No DEJAP, são oferecidos cursos de formação inicial e continuada para professores, cursos de Ensino Fundamental e Ensino Médio, e cursos técnicos para jovens e adultos nas modalidades presencial e à distância. Na Escola Básica, encontram-se os três níveis de ensino regular: Educação Infantil, Educação Fundamental e Ensino Médio.

O CEN é classificado como instituição filantrópica, não possuindo, por isso mesmo, fins lucrativos. Manteve-se dos anos sessenta ao final dos anos noventa como uma referência de práticas pedagógicas inovadoras, constituindo-se como um importante espaço de estágio para os cursos de formação de professores das redes públicas e privadas, bem como um privilegiado lócus de formação continuada.

Levando em conta sua importância regional para o campo da educação, buscamos neste texto entender algumas das articulações históricas que possibilitaram o surgimento do Centro Educacional de Niterói como uma escola filiada a um projeto nacional de "modernidade". Objetivamos também refletir acerca de concepções e ações que deram vida a essa instituição, e que se constituíram matrizes e diretrizes filosóficas das quais discursos e práticas, ao longo do tempo, passaram a ser herdeiros. A história do CEN nos permite compreender os movimentos e políticas produzidas neste tempo histórico e apontar elementos para os tempos que seguem, não a partir de uma relação linear, mas de aspectos que se interpenetram e se retroalimentam.

Privilegiamos neste texto, como já mencionado, o “Projeto Político Pedagógico do Centro Educacional de Niterói" (CENTRO EDUCACIONAL DE NITERÓl, 2003) como documento histórico e material de nossas reflexões. O destaque dado a tal documento na pesquisa residiu no fato de ter sido ele uma tentativa de expressar - e à época de sua elaboração uma tentativa de reafirmar - os principais aspectos que traduziriam a história e, de maneira especial, a identidade do CEN, considerados pela comunidade escolar como ameaçados de descaracterização, frente ao ápice de uma crise administrativo-financeira atravessada pela instituição a partir do final da década de 


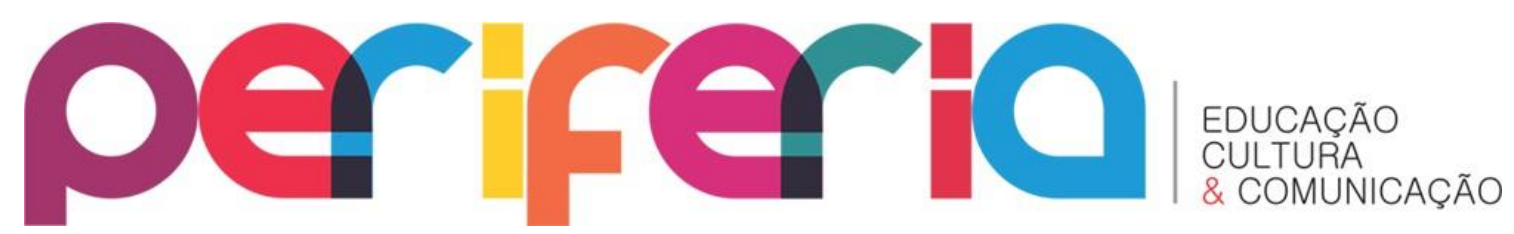

noventa.

O PPP do CEN - como chamaremos daqui por diante o "Projeto Político Pedagógico do Centro Educacional de Niterói" (CENTRO EDUCACIONAL DE NITERÓI, 2003) - foi elaborado a partir de discussões com os vários segmentos da comunidade, desde alunos da Educação Infantil até ex-alunos, pais, professores e funcionários. Em triangulação com um diagnóstico realizado por meio de questionários que estabeleceu as aspirações da comunidade escolar com relação à escola, o PPP do CEN do ano de 2003 se configurou, portanto, como um documento mestre, reafirmando sua história, construída coletivamente, como também projetando seus sonhos em uma tentativa de garantir a sobrevivência de seus fazeres e saberes.

O trecho a seguir sintetiza a missão da escola, como também explicita valores e pressupostos constituintes de sua identidade:

[...] a essência da missão do CEN é a formação integral da pessoa inserida no espaço que a cerca e no tempo do qual ela emerge, contribuindo, ao mesmo tempo, para a formação ética, o desenvolvimento da autonomia moral e intelectual e do pensamento crítico, de forma a poder intervir na realidade. Por isso, sempre ocuparam espaço importante dentro desse processo as atividades interdisciplinares, a participação consciente - que desperta no indivíduo o sentimento de responsabilidade para com os problemas sociais - a interação com o ambiente de trabalho e a autoeducação. Procurou-se sempre ultrapassar os muros da Escola, numa visão de educação que convida à ruptura das fronteiras de tempo e espaço. (CENTRO EDUCACIONAL DE NITERÓI, 2003, p. 30)

Outro fragmento do documento reflete a preocupação da comunidade escolar quanto aos princípios filosóficos e éticos que regiam aquela instituição:

[...] a grande esperança depositada na educação está no resgate do verdadeiro humanismo, que visa a recuperação do homem como sujeito de mudança e de todas as conquistas históricas, destacandose as sociais, econômicas, científicas e tecnológicas, na perspectiva de preservação da integridade humana e de estímulo à solidariedade. O pressuposto primeiro, contudo, é o da liberdade, sem o qual não seria possível educar-se, transformar-se. Da mesma forma, como o ato de educar supõe a escolha de uma atitude diante do outro, a busca de uma referência ética é princípio fundamental. (CENTRO EDUCACIONAL DE NITERÓl, 2003, p. 29). 


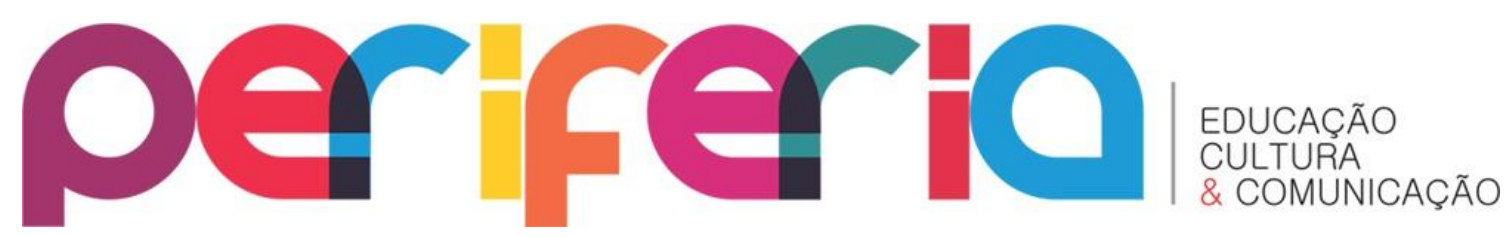

Esses pressupostos estão em consonância com o que diz o "Regimento Interno do Centro Educacional de Niterói” (FUNDAÇÃO BRASILEIRA DE EDUCAÇÃO, 2004). Ambos enfatizam a formação global da pessoa como condição facilitadora para a participação ativa do sujeito na construção de uma sociedade mais livre, democrática, cooperativa e justa.

Em 2007 a gestão administrativa, financeira e pedagógica da escola foi entregue a Rede de Ensino Futuro Vip, com várias unidades espalhadas principalmente pela região metropolitana do Rio de Janeiro e por outros municípios do Estado do Rio. Essa mudança, ocorrida como consequência de uma grave crise financeira do CEN, acirrou tensões e aprofundou certas reflexões relativas aos modelos de instituições de ensino privada.

Neste sentido, trechos do PPP como os que vemos baixo, convidavam a comunidade escolar a retomar certos acordos e consensos quanto à concepção de ensino e aprendizagem.

Para nós do Centro Educacional de Niterói, educar crianças e jovens significa ter como horizonte a leitura do mundo, o resgate da experiência e a construção de um sonho. Sonho que significa (re) escrever a história, pois, como diz Walter Benjamin, "cada época sonha não somente a seguinte, mas ao sonhá-la, força-a a acordar." (CENTRO EDUCACIONAL DE NITERÓI, 2003, p.13).

No fragmento do documento acima vemos que se estabelece o compromisso institucional com a reflexão sobre a experiência acumulada bem como com a construção de ações pedagógicas com vista à inovação. Assim, podemos perceber uma dupla mensagem à comunidade escolar: ao mesmo tempo em que se diz vinculada a concepções de educação ancoradas na ideia de inovação, modernidade e futuro, o CEN afirma seu compromisso com a tradição, já que permanências são elementos vistos como definidores de certa identidade.

Podemos entender, todavia, que o compromisso assumido pela instituição através de seu "Projeto Político Pedagógico" não é somente com a experiência acumulada, mas também com a reflexão acerca de si, o que significa carregar uma 


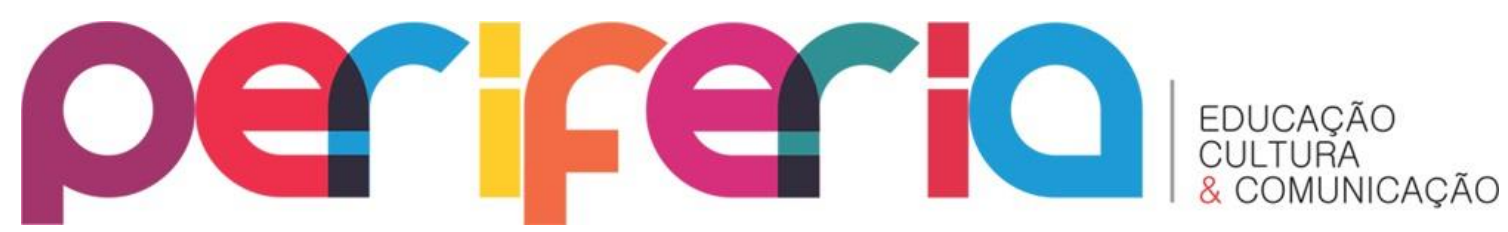

perspectiva de inovação - ou de "movimento alternativo", como ficou mais conhecido à época. As ações educativas do CEN, portanto, possuíam um triplo sentido: conciliar realidade (leitura de mundo), tradição (resgate da experiência) e inovação (construção de um sonho).

A percepção desse ponto fundamenta-se na interessante discussão que Burke (2007) propõe sobre tradição. Suas considerações e em especial sua pergunta nos provoca:

Dois problemas só, porém grandes: o problema da pureza e o problema da inovação. Problemas opostos e complementares, dois aspectos da mesma questão; quando, em quais circunstâncias, uma tradição deixa de ser tradição? (BURKE, 2007, p. 17).

O autor alerta que a relação entre a tradição e a inovação é "um tema cheio de paradoxos" (BURKE, 2007, p. 20). Paradoxos que se expressam no fazer cotidiano da educação já que a prática educativa, para ele, lida com objetivos incompatíveis: “Dum lado, transmitir para os alunos o patrimônio de conhecimento, a tradição, [que pode se tornar recurso ou peso no fazer pedagógico] e doutro lado, incentivar o espírito crítico, o pensamento independente" (BURKE, 2007, p. 20). Para Burke as instituições têm sua cultura e consequentemente sua história cultural, o que reafirma a dificuldade de se distinguir tradição e inovação. Diz o autor: "Às vezes, a inovação aparente esconde a persistência da tradição; outras vezes, a continuidade aparente disfarça inovações" (BURKE, 2007, p. 20).

Desta forma, pensar na relação entre inovação e tradição como constitutiva da identidade do Centro Educacional de Niterói é pensar em uma dinâmica complexa, como nos ensina Morin (2005) e não linear ou causal.

Por outro lado, a origem da criação do CEN está intimamente ligada à elaboração e implementação de um projeto mais amplo, de natureza nacional: a “modernização", tanto social e política, quanto educativa.

\section{O CONTEXTO HISTÓRICO DA CRIAÇÃO DA FUBRAE E DO CEN}

Conforme encontramos no documento "Projeto Político Pedagógico do CEN", a 


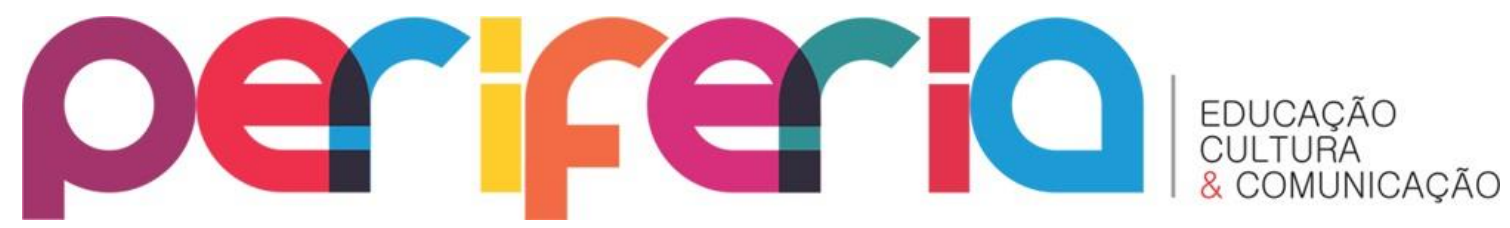

FUBRAE, fundação que deu origem ao Centro Educacional de Niterói, foi criada em 1955 com o nome de Fundação do Ensino Secundário, a partir da associação de "personalidades do meio educacional, cultural e empresarial do país" (CENTRO EDUCACIONAL DE NITERÓI, 2003, p. 9). Esteve sob a liderança, como gestor, do professor Armando Hildebrand, que, no período de 1953 a 1955, exerceu o cargo de Diretor de Ensino Secundário do Ministério da Educação.

Segundo Pedrosa (2002), a iniciativa de criação da FUBRAE e depois do Centro Educacional de Niterói faz parte de um conjunto de iniciativas que expressa "talvez o período mais fértil da história da educação no Brasil." (PEDROSA, 2002, p. 42). Ainda segundo a pesquisadora, entre essas iniciativas da década de 50 e dos anos iniciais da década de 60, destacam-se: a inauguração do Centro Popular de Educação por Anísio Teixeira, dando início à sua ideia de escola-classe e escola-parque; a elaboração, por Lauro de Oliveira Lima, de uma didática baseada nas teorias científicas de Jean Piaget: o Método Psicogenético; a campanha de alfabetização "De Pé no Chão Também se Aprende a Ler", a didática alfabetizadora criada por Paulo Freire; e a criação do Plano Nacional de Educação e do Programa Nacional de Alfabetização, pelo Ministério da Educação e Cultura, inspirado no Método Paulo Freire.

Tais iniciativas encontraram lugar porque,

\begin{abstract}
Na década de 1950, a América Latina foi marcada pela gradual transformação de suas condições socioeconômicas e políticas. No bojo dessas transformações, parcela significativa de técnicos, burocratas, políticos, economistas e cientistas sociais mobilizou-se em torno do tema da aceleração e consolidação do processo de desenvolvimento econômico e social de seus respectivos países uma mobilização conseguida pela elaboração do que se denominou de "ideário desenvolvimentista". (MENDONÇA et al., 2006, p. 96-97).
\end{abstract}

As mudanças promoveram discussões acerca da necessidade de formar e qualificar profissionais para as diversas áreas de atuação no país, principalmente para a pesquisa e docência. As finalidades e objetivos dessas instituições, expressos em seus atos de criação, revelam as necessidades daquele momento histórico.

De acordo com Pinto (2008), em decorrência das circunstâncias que envolviam 


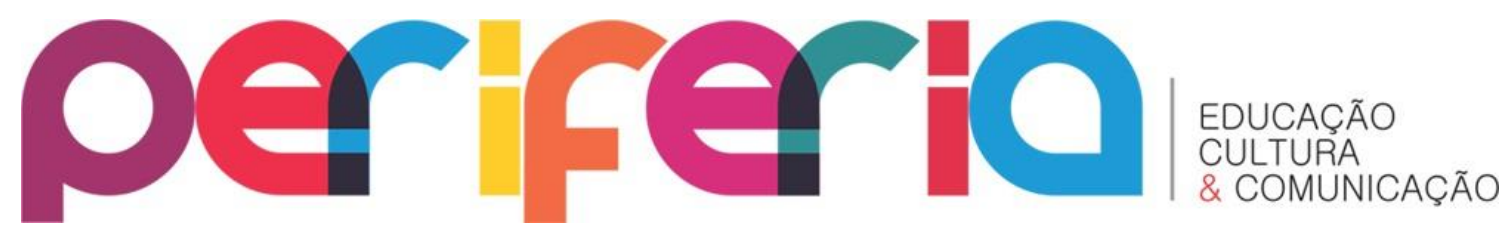

esse período, a educação escolar passou a ter novo sentido e a demanda pela educação secundária começou a aumentar fortemente. Segundo a autora, a Reforma Capanema (como ficou conhecida a Lei Orgânica do Ensino Secundário, de 9 de abril de 1942) colocou o ensino superior em evidência como via privilegiada de ascensão social e econômica. Por outro lado, “a Constituição de 1937 endereçara o ensino profissionalizante às classes menos favorecidas. Esses fatos combinados contribuíram para aumentar o prestígio do ensino secundário e reforçar a discriminação existente em relação ao ensino profissionalizante" (PINTO, 2008, p. 150).

Ainda segundo os dados pesquisados por Pinto (2008, p. 150), no período 19331950 o ensino primário havia crescido $90 \%$, o ensino superior, $80 \%$, enquanto o ensino secundário crescera $490 \%$. As preocupações percebidas pela pesquisadora nos escritos da época referem-se tanto ao atendimento das "necessidades e exigências de um país que se acreditava em franco desenvolvimento" como ao déficit de professores, principalmente os de nível secundário, cujo corpo docente [...] "era basicamente constituído por profissionais liberais (advogados, farmacêuticos, médicos, engenheiros), padres e normalistas." (PINTO, 2008, p. 151).

Diante desse quadro, medidas que modernizassem a educação, ainda sob a legislação do Estado Novo (1937-1945), pareciam inevitáveis.

É nesse contexto, no final dos anos 1950, e a partir dessas iniciativas, portanto, que o Professor Armando Hildebrand, presidente da FUBRAE e idealizador do CEN, convida a professora Myrthes de Luca Wenzel, que também trabalhava no Ministério da Educação, mais precisamente na Inspetoria de Ensino, para criar uma instituição de ensino que, segundo seu desejo, seria "uma escola diferente".

Conforme Lôbo (2002), na década de 50, D. Myrthes concluiu sua graduação em Geografia e História na Universidade do Distrito Federal (atual Universidade Estadual do Rio de Janeiro - UERJ). Lá, passou a integrar um grupo que, sob a direção da educadora Henriette de Holanda Amado (casada com Gilson Amado, idealizador da TV Educativa e futuro instituidor da FUBRAE), implantou, em 1957, no então Ginásio Público Brigadeiro Schorcht (atual Colégio Estadual de mesmo nome, inaugurado em 


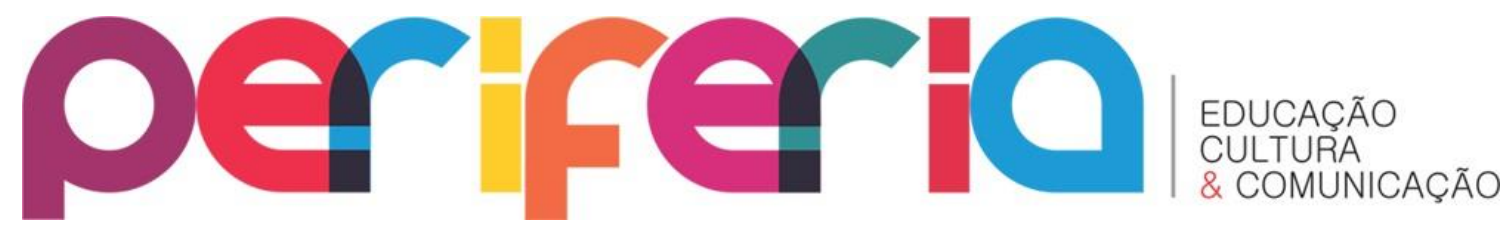

1956, em Jacarepaguá), "uma escola diferente", como ela própria relata:

Eu sou fundadora daquele grupo de professores que Henriette reuniu no Brigadeiro Schorcht... os professores do Brigadeiro implantaram uma escola diferente... fornecendo aos seus alunos a oportunidade de desenvolvimento intelectual e emocional, ensinando os alunos a amar o saber, a buscar o saber, a aprender a aprender, a gostar da arte, da música, da pintura... a participar dos clubes de Geografia, de Ciências, de Inglês e Francês. ... aos sábados ainda íamos dançar no Brigadeiro Schorcht. E, assim, tivemos uns anos muito agradáveis... tudo começou lá, no Brigadeiro Schorcht, colégio dirigido pela ilustre educadora Henriette Amado, a quem presto minha homenagem. (LÔBO, 2002, p. 6-7).

Segundo descreve Lôbo (2002), o grupo fundador do Brigadeiro Schorcht desejava criar uma escola "em que os alunos pudessem ser felizes, com liberdade de criar, de viver em sociedade e, ao mesmo tempo, ser preparados de modo completo e científico para participar da vida social." (LÔBO, 2002, p.7). O programa do ginásio era constituído por atividades obrigatórias comuns, de caráter técnico-científico e de formação geral, e por atividades de livre escolha do aluno, como música, arte, línguas, que eram desenvolvidas em clubes. O diferencial dessa iniciativa reside em "as atividades em grupos, onde a cooperação se constitui elemento operativo do programa escolar." (LÔBO, 2002, p. 7). Muitas atividades eram realizadas fora de sala de aula, inclusive as aulas de Geografia da Prof. Myrthes, que, aproveitando a topografia e o entorno rural, levava os alunos a escaladas e pescas. Para Lôbo, esses "indícios parecem indicar a influência de Célestin Freinet na orientação que Henriette Amado procurou dar ao Colégio." (2002, p. 7).

A essa época, como atividade da CADES, D. Myrthes, que também era inspetora do Ministério da Educação, passou a dar cursos de Geografia para professores de todo o Brasil. As experiências do Brigadeiro Schorcht foram publicadas pela Editora do Brasil, no início da década de 1960, em livro de D. Myrthes em coautoria com Hilda Fernandes Mattos, que passou a ser utilizado pela CADES.

Pode-se perceber que as políticas defendidas por Anísio Teixeira, à frente do INEP, a experiência de Myrthes no Brigadeiro Schorcht e a sua atuação na CADES, 


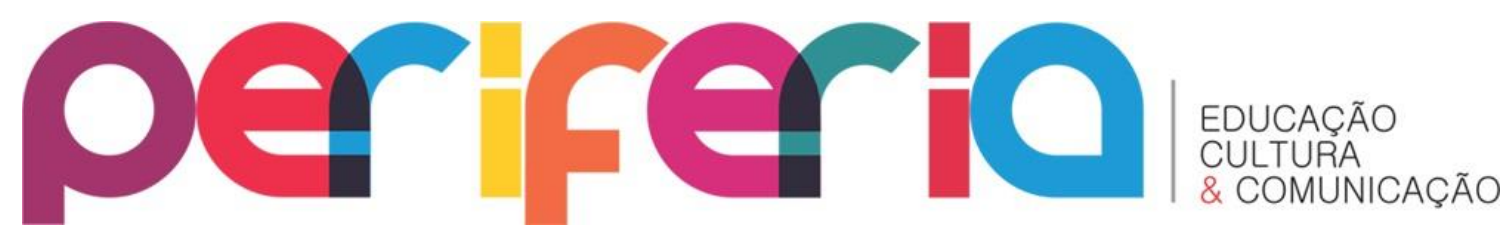

conduzida por Armando Hildebrand, concorreram para que ela fosse escolhida para estar à frente da fundação do Centro Educacional de Niterói. Sobre isso, diz Myrthes: "Quando fui convidada pela Fundação Brasileira de Educação para abrir uma escola diferente, uma escola de formação que desse ao aluno oportunidade de desenvolvimento, de trabalho, imaginei tudo aquilo que fazíamos no Brigadeiro Schorcht." (LÔBO, 2002, p. 8).

Segundo Lôbo,

A extensão do experimento [Brigadeiro Schorcht] dá condições para a disseminação de princípios de uma teoria da educação fundamentada na liberdade do aluno e do professor (que pode experimentar propostas curriculares alternativas) e no caráter progressista e libertário da escola (que D. Myrthes chamou de "Escola aberta"), que se consolida no modelo do Centro Educacional de Niterói. (LÔBO, 2002, p. 8).

A fala de D. Myrthes corrobora o entendimento sobre a estreita ligação entre o ideário deweyano, as propostas dos Ginásios da Comunidade, implementados por Lauro de Oliveira Lima, o Ginásio Brigadeiro Schorcht e o Centro Educacional de Niterói.

Ainda sobre a escola com que D. Myrthes sonhava, diz ela em entrevista para um documentário sobre o CEN, dada a uma ex-aluna:

Os professores também querem escolas criativas. Os professores que, às vezes, não se desempenham bem é porque, às vezes, não encontram campo para se desempenhar. Correu um boato em Niterói, e o boato atravessou a baía, é que lá em Niterói um educador "pra frente", Armando Hildebrand, ia criar uma escola diferente, onde os professores teriam liberdade, poderiam criar coisas novas; poderiam, em suma, se realizar como professores. A dificuldade foi dizer aos professores "Não tenho mais vagas, todas as vagas estão preenchidas". Eles foram buscar a escola com a qual eles sonhavam. (CARIELLO, 2010).

A professora Nícia Pereira Muniz, também convidada por Hildebrand à época da criação do CEN, e que foi vice-diretora da escola no período de 1962 a 2000, esclarece a respeito do ideário de "escola diferente", disse em uma conversa à época da pesquisa: 


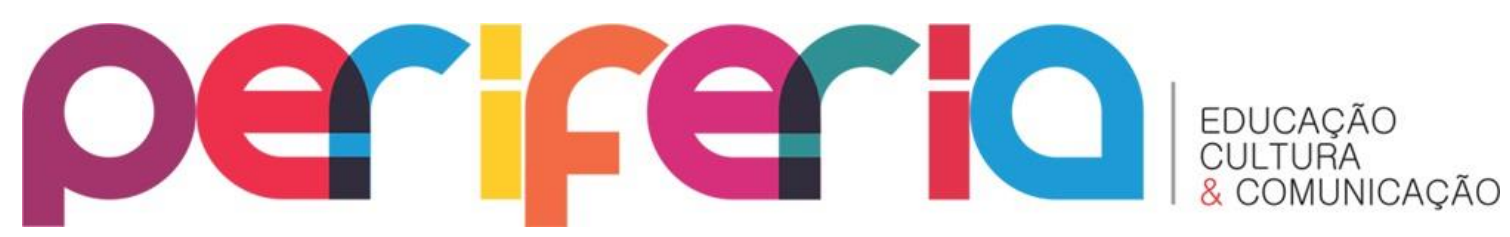

Eu acho que era diferente no sentido que não visava só levar um bom conteúdo ao aluno. Uma escola boa leva um bom conteúdo ao aluno, - ajuda a aprender aquilo "aprendido". Eu acho que ela se preocupava com a relação dele com os colegas, com a relação dele com os professores, com a relação dele com a família, com o desenvolvimento da capacidade de raciocínio dele... Eu acho que é diferente nesse sentido, porque naquela época não tinha, [a escola] era muito conteudista. (...) Eu acho que diferente é nesse sentido, de se preocupar com os vários aspectos da educação, e não só com o conteúdo. (informação verbal ${ }^{4}$ ).

De acordo com D. Nícia, o que fazia o CEN ser compreendido como diferente da maior parte das escolas da época não consistia em uma oposição, mas no que ela acreditava ser uma ampliação do papel da escola. O discurso produzido no interior do CEN com ressonâncias para fora da escola, a reafirmava como um espaço educativo onde o "conteúdo" deveria ser uma das dimensões da educação, não a única, nem a maior.

Originalmente em sua concepção de aprendizagem, os chamados "conteúdos escolares" deveriam ser aprendidos como resultado de processos de compreensão, e não simplesmente memorizados. Essa concepção, porém, não era vivida sem contradições ou conflitos.

Eles diziam que os alunos do Centro não sabiam nada, porque a gente não dava conteúdo, entende? Eles não sabem o que é conteúdo, conteúdo para eles é aquele massacre de você decorar uma lei, decorar um cálculo, uma fórmula. Se você dá o conteúdo bem dado, você dá possibilidade de ele [o aluno] usar aquilo que ele aprendeu em outras situações. Eu entendo que é isso, porque naquela época, realmente, o Centro [era diferente]. (informação verbal $\left.{ }^{5}\right)$.

As falas de D. Myrthes e de D. Nícia corroboram a visão de que o CEN teria sido idealizado para ser um espaço de experimentação e inovação, apesar de possuir inúmeras contradições. A idealização do CEN reflete, segundo Santos:

[...] a efervescência deste momento da política educacional brasileira, [...] e que possibilitou a existência de um "solo fértil" para o

\footnotetext{
${ }^{4}$ Entrevista concedida por Nícia Pereira Muniz a Ana Cristina Carpi, em 20 set. 2013.

${ }^{5}$ Entrevista concedida por Nícia Pereira Muniz a Ana Cristina Carpi, em 20 set. 2013.
} 


\section{periferio}

desenvolvimento de iniciativas pedagógicas experimentais. (SANTOS, 2010, p. 41).

A presença de Anísio Teixeira à frente do INEP, órgão que teve enorme influência na educação daquele período foi, ainda segundo o autor, outro motivo pelo qual iniciativas experimentais na educação ocorreram. O INEP se mostrava abertamente favorável ao chamado "experimentalismo pedagógico", especialmente aquele ligado as ideias de John Dewey. Para Mendonça e outros (2006), tal apoio se devia também pelo fato de que:

[...] "a escola progressiva", experimental e não-dualista, era percebida como a única capaz de se constituir em um agente de mudança cultural e, consequentemente, contribuir para a formação de uma consciência comum favorável ao desenvolvimento brasileiro. (MENDONÇA et al, 2006, p. 104-105).

Se o "ideário deweyano" influenciou uma época, também recebeu de Armando Hildebrand uma atenção especial na construção pedagógica da escola que ficaria conhecida como CEN.

As orientações pedagógicas que constituíam as "iniciativas experimentais", mesmo provindo de bases teóricas distintas, tinham pontos em comum: ênfase nos métodos ativos, no atendimento aos interesses do aluno, no oferecimento de atividades diversificadas e no deslocamento do foco do professor para o aluno no processo educacional. A criação do Centro Educacional de Niterói, portanto, estava ligada tanto à expansão do ensino médio dos aos 60, quanto à implementação de um modelo escolanovista, de base deweyana.

D. Myrthes permaneceu à frente do Centro Educacional de Niterói desde a sua fundação até o ano de 1999, estando afastada somente no período de 1975 a 1979, quando assumiu a Secretaria Estadual de Educação do então recém-criado Estado do Rio de Janeiro.

A preocupação de Armando Hildebrand, fundador da FUBRAE e idealizador no CEN, não se limitava somente à formação da criança e do adolescente. Como implementador da Campanha de Aperfeiçoamento e Difusão do Ensino Secundário, 


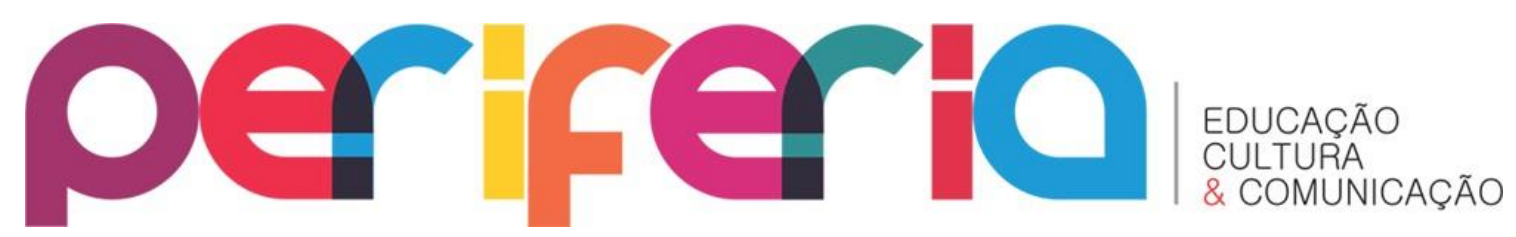

Hildebrand dirigiu especial foco em suas ações para a formação de professores. Essa foi também uma marca identitária do CEN, percebida não só pela existência no CEN e na FUBRAE de órgãos da escola e da fundação ligados a essa formação, presencial e depois à distância, como pela diversidade de espaços formativos dentro da própria escola voltados para seus professores.

\section{CONCLUSÕES}

Neste artigo buscamos refletir acerca das condições históricas e políticas que permitiram a criação, em 1955, da Fundação de Ensino Secundário (atual FUBRAE) e posteriormente o CEN. A análise deste contexto nos permitiu concluir que a criação desta instituição educativa estava relacionada à luta maior pela hegemonia no campo educacional de modelos pedagógicos e administrativos ligados ao ideário da Escola Nova. Apesar de procurar manter-se fiel à proposta de implementação de inovações no campo pedagógico, o CEN foi aos poucos sucumbindo a um conjunto de problemas que vão desde dificuldades financeiras institucionais até o acirramento de políticas neoliberais que comprometeram políticas sociais e de educação, levando a escola a perder ou ver fortemente atenuadas as suas marcas identitárias mais significativas.

O Centro Educacional de Niterói é, atualmente, uma das duas unidades operacionais da Fundação Brasileira de Educação (FUBRAE) em atuação, sendo a segunda o Centro de Ensino Tecnológico de Brasília (CETEB). O DEJAP ainda funciona em parte das instalações construídas para o funcionamento do CEN em um terreno doado pelo então governo estadual Miguel Couto Filho (1954-1958), na Avenida Amaral Peixoto, em Niterói. O restante dessas edificações está atualmente ocupado por instituições outras, para fins diversos. A unidade de Educação Básica funciona em sua totalidade em prédios situados em uma ampla área no bairro do Pé Pequeno.

Mesmo sendo para muitos apenas mais uma escola privada em Niterói, sua origem e trajetória revelam histórias atravessadas por personagens que sonhavam mudar a educação nacional. Um tempo de utopias que deixou marcas que, agora, podemos perscrutar e (re)conhecer. 


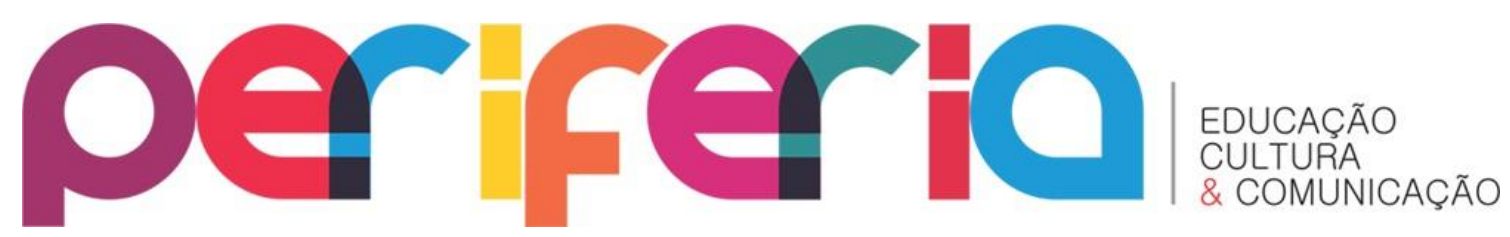

\section{REFERÊNCIAS}

BARDIN, Laurence. Análise de conteúdo. Lisboa: Edições 70; LDA, 2009.

BURKE, Peter. Cultura, tradição, educação. In: GATTI JR., Décio; PINTASSILGO, Joaquim (Orgs.). Percursos e desafios da pesquisa e do ensino de História da Educação. Uberlândia: EdUFU, 2007.

CARIELLO, Ingrid. Nossa escola tem história. Rio de Janeiro, 2010. Disponível em: <http://www.youtube.com/watch?v=XGT4q_CsEAQ>. Acesso em: 21 jun. 2013.

CARPI, Ana Cristina M. dos S. Tornar-se doCENte: uma viagem pelas experiências formativas de professores da Educação Infantil do Centro Educacional de Niterói. 2014. 218 f. Dissertação (Mestrado em Educação)-Faculdade de Formação de Professores da Universidade Estadual do Rio de Janeiro, São Gonçalo, 2014.

CENTRO EDUCACIONAL DE NITERÓI. Projeto Político Pedagógico. Niterói, 2003. 67 p. Mimeografado.

FUNDAÇÃO BRASILEIRA DE EDUCAÇÃO. Estatuto da Fundação Brasileira de Educação 1992. Brasília, DF, 1994. Mimeografado.

- Regimento Interno do Centro Educacional de Niterói. Niterói, 2004.

Mimeografado.

LÔBO, Yolanda Lima. D. Myrthes: a Secretária de Educação e Cultura da fusão. In: CONGRESSO BRASILEIRO DE HISTÓRIA DA EDUCAÇÃO, 2., 2002, Natal. Anais... Natal:

UFRN, 2002. $\quad$ v. 1, p. 1-11. Disponível em: <http://www.sbhe.org.br/novo/congressos/cbhe2/pdfs/Tema4/0480.pdf>. Acesso em: 21 jun. 2013.

MENDONÇA, Ana Waleska Pollo Campos et al. Pragmatismo e desenvolvimentismo no pensamento educacional brasileiro dos anos de 1950/1960. Revista Brasileira de Educação, Rio de Janeiro, v. 11, n. 31, jan./abr. 2006.

MORIN, Edgar. Introdução ao pensamento complexo. Porto Alegre: Sulina, 2005.

PEDROSA, Maria Elisa Pennafirme. Centro Educacional de Niterói: uma história de experimentação pedagógica. 2002. Dissertação (Mestrado em Educação)-Universidade do Estado do Rio de Janeiro, Rio de Janeiro, 2002.

PINTO, Diana Couto. Campanha de aperfeiçoamento e difusão do ensino secundário: uma trajetória bem sucedida? In: MENDONÇA, Ana Waleska Pollo Campos; XAVIER, Libânia Nacif (Orgs.). Por uma política de formação do magistério nacional: o INEP/MEC dos anos 1950/1960. Brasília, DF: INEP, 2008.

SANTOS, Pablo S. M. B. O público, o privado e o ensino fluminense (1954-1970): o caso do Centro Educacional de Niterói. 2010. 195 f. Tese (Doutorado em Educação)Pontifícia Universidade Católica do Rio de Janeiro, Rio de Janeiro, 2010. 